NISTLER, Regiane. Hermenêutica jurídica e intervencionismo judicial: conceitos gerais e fenômenos relacionados. Revista Eletrônica Direito e Política, Programa de Pós-Graduação Stricto Sensu em Ciência Jurídica da UNIVALI, Itajaí, v.14, n.2, $2^{\circ}$ quadrimestre de 2019. Disponível em: www.univali.br/direitoepolitica - ISSN 1980-7791

\title{
HERMENÊUTICA JURÍDICA E INTERVENCIONISMO JUDICIAL: CONCEITOS GERAIS E FENÔMENOS RELACIONADOS
}

\author{
LEGAL HERMENEUTICS AND JUDICIAL INTERVENTION: GENERAL CONCEPTS \\ AND RELATED PHENOMENA
}

Regiane Nistler ${ }^{1}$

\begin{abstract}
RESUMO
O presente artigo científico aborda a hermenêutica jurídica e o intervencionismo judicial. Tem como objetivo principal contextualizar a hermenêutica jurídica e seus fenômenos relacionados, especialmente ao analisar o ativismo judicial, a judicialização da política e suas diferenciações. Tem como objetivo secundário esclarecer brevemente alguns conceitos gerais importantes da hermenêutica jurídica. Neste intento, serão explicadas noções de discricionariedade judicial, teoria da decisão, racionalidade, resposta correta e constitucionalismo. O método usado na confecção do trabalho foi o indutivo. O levantamento de dados embasado na pesquisa bibliográfica doutrinária. As áreas jurídicas predominantes no estudo foram o direito público e o direito constitucional, notadamente a hermenêutica jurídica.
\end{abstract}

PALAVRAS-CHAVE: Ativismo judicial; Constitucionalismo; Discricionariedade judicial; Judicialização da política.

\begin{abstract}
This scientific article approaches the legal hermeneutics and judicial interventionism. Its main objective is to contextualize legal hermeneutics and its related phenomena, especially when analyzing judicial activism, the judicialization of politics and its differentiations. It has as secondary objective to clarify briefly some important general concepts of legal hermeneutics. In this attempt, it will be explained notions of judicial discretion, decision theory, rationality, correct response and constitutionalism. The method used in the making of the work was the inductive one. The data collection based on doctrinal bibliographical research. The predominant legal areas in the study were public law and constitutional law, notably legal hermeneutics.
\end{abstract}

KEYWORDS: Judicial activism; Constitutionalism; Judicial discretion; Judicialization of politics.

\footnotetext{
${ }^{1}$ Doutoranda em Direito pela Universidade Estácio de Sá - UNESA, campus do Rio de Janeiro (RJ). E-mail: regianenistler@outlook.com.
} 
NISTLER, Regiane. Hermenêutica jurídica e intervencionismo judicial: conceitos gerais e fenômenos relacionados. Revista Eletrônica Direito e Política, Programa de Pós-Graduação Stricto Sensu em Ciência Jurídica da UNIVALI, Itajaí, v.14, n.2, $2^{\circ}$ quadrimestre de 2019. Disponível em: www.univali.br/direitoepolitica - ISSN 1980-7791

\section{INTRODUÇÃO}

Houve uma perceptível mudança na postura de atuação do Supremo Tribunal Federal (STF) nos últimos anos. O órgão representativo máximo do Judiciário brasileiro passou cada vez mais a desempenhar de forma protagonista atribuições privadas e públicas que outrora não eram de sua competência. Esta ampliação unilateral da sua capacidade decisória ocasionou e ainda acarreta significativas perturbações na estrutura institucional e na vida dos brasileiros.

Esta crescente tendência se tornou indiscutivelmente polêmica, repercutindo sobremaneira no cenário jurídico nacional. Tem sido alvo de recentes protestos e aplausos e, não obstante seja uma discussão relativamente nova aqui, não é um assunto exclusivamente pátrio. Este fenômeno conhecido como "ativismo judicial" há bastante tempo está inserto nas pautas internacionais. Outro fenômeno que compartilha semelhante controvérsia é a "judicialização da política".

Referido "evento", também integrante do pacote intervencionista judicial, manifesta-se contingencialmente, buscando dirimir no âmbito judicial questões governamentais e institucionais cujos funcionamentos estejam em desacordo com os ditames constitucionais. Enquanto esta judicialização política pode desencadear resultados positivos ou negativos, a depender do nível de adequação constitucional da sua resposta, um ativismo judicial decide substituindo o debate público.

Não obstante a relevância e influência constitucionalista para com estes fenômenos mencionados alhures - particularmente no que diz respeito ao avanço do constitucionalismo e da concretização dos direitos fundamentais - os quais foram e são deveras observados e estudados nas nações europeias e pelo direito americano, impende por ora investigar suas principais características e implicações relativas ao nosso ordenamento jurídico pátrio.

Neste sentido, vale-se da hermenêutica jurídica - área responsável, em linhas gerais, pela interpretação das normas jurídicas mediante métodos racionais e elementos textuais e extratextuais - que, em seu viés constitucional, também procura compreender os fenômenos do ativismo judicial e da judicialização da política. Dispõe-se, portanto, das noções de discricionariedade judicial, teoria da 
NISTLER, Regiane. Hermenêutica jurídica e intervencionismo judicial: conceitos gerais e fenômenos relacionados. Revista Eletrônica Direito e Política, Programa de Pós-Graduação Stricto Sensu em Ciência Jurídica da UNIVALI, Itajaí, v.14, n.2, $2^{\circ}$ quadrimestre de 2019. Disponível em: www.univali.br/direitoepolitica - ISSN 1980-7791

decisão, racionalidade, resposta correta e do constitucionalismo para elucidação da temática proposta.

Objetiva-se desta forma, com este artigo científico, contextualizar a hermenêutica jurídica e seus fenômenos relacionados, especialmente ao analisar, nos últimos tópicos, o ativismo judicial, a judicialização da política e suas distinções; almejase também esclarecer propedêutica e sinteticamente, nos primeiros tópicos do estudo, como objetivos secundários, alguns conceitos gerais importantes da hermenêutica jurídica.

O principal método utilizado na elaboração deste trabalho foi o indutivo. 0 levantamento de dados foi baseado na pesquisa doutrinária. As áreas jurídicas preponderantes no desenvolvimento deste são as áreas do direito público e do direito constitucional, notadamente a hermenêutica jurídica, cujo expoente no assunto em terrae brasilis é Lenio Luiz Streck, motivo pelo se buscou sobremaneira na produção literária do jurista.

\section{DISCRICIONARIEDADE JUDICIAL}

Segundo Lenio Luiz Streck, a discricionariedade consiste na característica maior do positivismo jurídico. Trata-se de um poder arbitrário que reside nas mãos dos magistrados para preencher as lacunas legais ${ }^{2}$. Contudo, adverte referido doutrinador que não deve ser confundido arbitrariedade do juiz com atos discricionários e atos vinculados da administração pública:

Nesse sentido, discricionariedade, no modo como ela é praticada no Direito brasileiro, acaba, no plano da linguagem, sendo sinônimo de arbitrariedade. E não confundamos essa discussão - tão relevante para a teoria do Direito - com a separação feita pelo Direito administrativo entre atos discricionários e atos vinculados, ambos diferentes de atos arbitrários. Trata-se, sim, de discutir- ou, na verdade, pôr em xeque - o grau de liberdade dado ao intérprete em face da

\footnotetext{
2 STRECK, Lenio Luiz. Dicionário de hermenêutica: quarenta temas fundamentais da teoria do direito à luz da crítica hermenêutica do Direito. Belo Horizonte (MG): Letramento, 2017, p. 53.
} 
NISTLER, Regiane. Hermenêutica jurídica e intervencionismo judicial: conceitos gerais e fenômenos relacionados. Revista Eletrônica Direito e Política, Programa de Pós-Graduação Stricto Sensu em Ciência Jurídica da UNIVALI, Itajaí, v.14, n.2, $2^{\circ}$ quadrimestre de 2019. Disponível em: www.univali.br/direitoepolitica - ISSN 1980-7791

legislação produzida democraticamente, com dependência fundamental da Constituição ${ }^{3}$.

Imperioso alertar ainda, para fins de distinção e caracterização, que os atos discricionários são legalmente autorizados enquanto a discricionariedade judicial, aquela praticada pelos magistrados, não possui regulamentação. Com nada legislando a este respeito, abre-se brecha de presunção de que os atos judiciais discricionários inexistem e, por conseguinte, que incumbe ao próprio juiz da causa dispor como bem entender. Neste sentido, esclarece Streck:

Vale dizer, o ato discricionário é autorizado legislativamente. Ocorre que, no âmbito da interpretação judicial não nos encontramos diante da mesma situação. Aqui não há regulamentação legal a ser discutida, pelo contrário, pressupõe-se que ela inexiste. Assim o juiz efetivamente criará uma regra para regulamentar o caso a ele apresentado ${ }^{4}$.

Outra vertente conceitual acerca da discricionariedade costuma divergir quanto à amplitude do poder discricionário judicial ${ }^{5}$. Enquanto a primeira admite um vasto poder criativo ao julgador da causa, esta segunda linha de pensamento defende este poderio ser limitado às potencialidades do ordenamento jurídico ${ }^{6}$. Inobstante o posicionalmente, ambas convergem no sentido de haver uma determinada margem de escolha ao magistrado.

\section{TEORIA DA DECISÃO, RACIONALIDADE E RESPOSTA CORRETA}

Prosseguindo com a terminologia e conceituação, destaca-se a abordagem do paradigma hermenêutico de Lenio Streck, extremamente relevante no presente

\footnotetext{
3 STRECK, Lenio Luiz. Dicionário de hermenêutica: quarenta temas fundamentais da teoria do direito à luz da crítica hermenêutica do Direito. Belo Horizonte (MG): Letramento, 2017, p. 54.

4 STRECK, Lenio Luiz. Dicionário de hermenêutica: quarenta temas fundamentais da teoria do direito à luz da crítica hermenêutica do Direito. Belo Horizonte (MG): Letramento, 2017, p. 54.

5 STAFFEN, Márcio Ricardo. Magistrati. Novos Estudos Jurídicos, Itajaí, v. 18, n. 3, p. 569-570, dez. 2013.

6 TERRA, Aline de Miranda Valverde. A discricionariedade judicial na metodologia civil-constitucional. Revista da Faculdade de Direito - UFPR. Curitiba, vol. 60, n. 3. Set/dez. 2015. p. 368. Disponível em: <DOI: 10.5380/rfdufpr.v60i3.41141>. Acesso em: 1 dez. 2018.
} 
NISTLER, Regiane. Hermenêutica jurídica e intervencionismo judicial: conceitos gerais e fenômenos relacionados. Revista Eletrônica Direito e Política, Programa de Pós-Graduação Stricto Sensu em Ciência Jurídica da UNIVALI, Itajaí, v.14, n.2, $2^{\circ}$ quadrimestre de 2019. Disponível em: www.univali.br/direitoepolitica - ISSN 1980-7791

contexto, mormente porquanto o debate se conjuga nos dias atuais. Tanto é que, nas palavras de Lúcio Delfino e Ziel Ferreira Lopes:

É perceptível a convergência entre esses estudos cognitivos e a linha teórica defendida por Streck, pois os primeiros demonstram aquilo que a segunda desde há muito advoga: tornou-se indispensável uma Teoria da Decisão que sabote o solipsismo judicial reinante no país, fenômeno que reduz o direito meramente àquilo que dizem os juízes e os tribunais $[\ldots]^{7}$.

Denota-se, segundo este viés, a relevância da existência de criteriologias decisórias, de sorte que o posicionamento defendido por Streck, há um bom tempo, também passou a ser ratificado por outros saberes. Aliás, oportunas são as palavras de Lúcio Delfino e Ziel Ferreira Lopes:

Daí dizer-se que uma Teoria da Decisão (com criteriologia específica) servirá também para socorrer julgadores, mantendo-os alertas no momento em que realizam a atividade judicante, atentos à responsabilidade política inerente à sua função, auxiliando-os na criação de hábitos reflexivos distintos daqueles advindos do seu pensamento primitivo, ajudando-os, enfim, a impedir eventuais desvios $\operatorname{cognitivos}^{8}$.

Eis aqui um dos pilares ocultos do presente artigo, uma vez que já foi elucidado por modernas pesquisas neurocientíficas que, não raras as vezes, desvios cognitivos acabam proporcionando "automatismos mentais", os quais influenciarão na qualidade das decisões, tornando-se necessário soluções atenuantes para que se evitar o máximo possível discricionariedades judiciais. A propósito, elucida Juarez Freitas ${ }^{9}$ :

O fenômeno é imputável às seduções do impulsivismo, à insuficiência de cânones seguros, à usurpação de poderes, ao

\footnotetext{
7 DELFINO, Lúcio; LOPES, Ziel Ferreira. STRECK, FONSECA COSTA, KAHNEMAN E TVERSKY: todos contra o ativismo judicial probatório de Michele Taruffo. Revista de Processo (RePro), 255, 2016.

8 DELFINO, Lúcio; LOPES, Ziel Ferreira. STRECK, FONSECA COSTA, KAHNEMAN E TVERSKY: todos contra o ativismo judicial probatório de Michele Taruffo. Revista de Processo (RePro), 255, 2016.

9 FREITAS, Juarez. A Hermenêutica Jurídica e a Ciência do Cérebro: Como Lidar com os Automatismos Mentais. Revista Ajuris, 130. Porto Alegre: Associação dos Juízes do Rio Grande do Sul, 2013. p. 225.
} 
NISTLER, Regiane. Hermenêutica jurídica e intervencionismo judicial: conceitos gerais e fenômenos relacionados. Revista Eletrônica Direito e Política, Programa de Pós-Graduação Stricto Sensu em Ciência Jurídica da UNIVALI, Itajaí, v.14, n.2, $2^{\circ}$ quadrimestre de 2019. Disponível em: www.univali.br/direitoepolitica - ISSN 1980-7791

tráfico de influências, à má qualidade legislativa e à falta de autocontrole. Claro que todos esses fatores pesam, contudo só provocam estragos em função da concorrência subjacente de determinadas armadilhas mentais. São precisamente os vieses (bases) ou as distorções cognitivas que costumam levar o intérprete a erros sistemáticos de avaliação e controle. Ao dominarem a cena, as velhas regras de ouro da hermenêutica deixam de funcionar, ou se mostram constituídas de ouro falso.

Desta feita, discute-se as terminologias streckiana como uma maneira de adequação hermenêutica ao pensamento de Kahneman e Tversky. A este respeito, Lúcio Delfino e Ziel Ferreira Lopes tecem as seguintes ponderações:

i) suspensão dos pré-juízos, escapando aos ilegítimos sem perder, de resto, a positividade que já sustenta qualquer compreensão (que se antecipa, retifica e legitima na virtuosidade do círculo hermenêutico); ii) vigiar a eclosão de sentidos na abertura originária em que se desvela a verdade; iii) recuperar a dialética da pergunta e resposta; e iv) manter abertura ao diálogo com os outros (à fusão de horizontes) e com a tradição, em que se guarda um apriori compartilhado ${ }^{10}$.

Destarte, percebe-se que a terminologia empregada por Lenio Streck demonstra a alegada adaptação hermenêutica defendida por Kahneman e Tversky, a qual, frisa-se, não diz respeito apenas a questão da racionalidade, mas também a uma dada forma "viciada-em-si-mesma"11.

Outrossim, há vários fatores que acabam induzindo o surgimento de decisões incorretas do ponto de vista da racionalidade, o que torna laboriosa a constituição de uma justificativa coerente. Com efeito, é de extrema importância que o juiz esteja atento para não cair na endrômina da pré-compreensão que, por via de consequência, poderá vir a influenciar na tomada de decisão do julgador. Para tanto, Lenio Streck sugere o estabelecimento da chamada resposta correta, que se traduz da seguinte forma:

\footnotetext{
10 DELFINO, Lúcio; LOPES, Ziel Ferreira. STRECK, FONSECA COSTA, KAHNEMAN E TVERSKY: todos contra o ativismo judicial probatório de Michele Taruffo. Revista de Processo (RePro), 255, 2016.

11 DELFINO, Lúcio; LOPES, Ziel Ferreira. STRECK, FONSECA COSTA, KAHNEMAN E TVERSKY: todos contra o ativismo judicial probatório de Michele Taruffo. Revista de Processo (RePro). 255, maio 2016.
} 
NISTLER, Regiane. Hermenêutica jurídica e intervencionismo judicial: conceitos gerais e fenômenos relacionados. Revista Eletrônica Direito e Política, Programa de Pós-Graduação Stricto Sensu em Ciência Jurídica da UNIVALI, Itajaí, v.14, n.2, 20 quadrimestre de 2019. Disponível em: www.univali.br/direitoepolitica - ISSN 1980-7791

[...] Está ligada à superação do objetivismo e do subjetivismo. Por isso a noção de resposta correta é incompatível com pragmaticismos, realismos e todas as formas de positivismo. Resposta correta, finalmente, quer dizer que - a resposta nunca advirá antes das perguntas serem feitas. Perguntas implicam estabelecimento de critérios para encontrar respostas adequadas ${ }^{12}$.

A par disso, em razão dos critérios definidos por Streck, procura-se afugentar decisões distorcidas e julgamentos dissonantes por intermédio de discursos verdadeiros, ou seja, imbuídos de criteriologia. Nessa senda, Streck enumera as hipóteses em que o julgador pode deixar de aplicar a lei:

Assim, um juiz somente pode deixar de aplicar a lei em seis hipóteses: (i) quando a lei foi inconstitucional, ocasião em que se deve ser aplicada a jurisdição constitucional difusa ou concentrada; (ii) quando estiver em face do critérios de antinomias; (iii) quando estiver em face de uma interpretação conforme a Constituição; (iv) quando estiver em face de uma nulidade parcial com redução de texto; (v) quando estiver em face da inconstitucionalidade com redução de texto; (vi) quando estiver em face de uma regra que se confronte com um princípio, ocasião em que a regra perde sua normatividade em face de um princípio constitucional, entendido este como um padrão, do modo como explicitado em Verdade e Consenso $(2014 b ; 2017)^{13}$.

Além da sêxtupla motivação levantada por Streck para não aplicação da lei, o autor indica três indagações às quais o julgador deve responder:

[...] se está diante de um direito fundamental com exigibilidade, se $o$ atendimento a esse pedido pode ser, em situações similares, universalizado, quer dizer, concedido às demais pessoas e se, para atender aquele Direito, está-se ou não fazendo transferência ilegal-constitucional de recursos, que fere a igualdade e a isonomia ${ }^{14}$.

12 STRECK, Lenio Luiz. Dicionário de Hermenêutica: quarenta temas fundamentais da teoria do direito à luz da crítica hermenêutica do direito. Belo Horizonte: Letramento, 2017, p. 258.

13 STRECK, Lenio Luiz. Dicionário de Hermenêutica: quarenta temas fundamentais da teoria do direito à luz da crítica hermenêutica do direito. Belo Horizonte: Letramento, 2017, p. 258-259.

14 STRECK, Lenio Luiz. Dicionário de Hermenêutica: quarenta temas fundamentais da teoria do direito à luz da crítica hermenêutica do direito. Belo Horizonte: Letramento, 2017, p. 259. 
NISTLER, Regiane. Hermenêutica jurídica e intervencionismo judicial: conceitos gerais e fenômenos relacionados. Revista Eletrônica Direito e Política, Programa de Pós-Graduação Stricto Sensu em Ciência Jurídica da UNIVALI, Itajaí, v.14, n.2, $2^{\circ}$ quadrimestre de 2019. Disponível em: www.univali.br/direitoepolitica - ISSN 1980-7791

Consubstanciado nestas indagações que Lenio Streck busca analisar se o ato judicial é ativista ou se o mesmo está empreendendo a judicialização da política (termos que serão melhor abordados nos tópicos seguintes), de modo que, havendo a negativa de qualquer uma delas, estar-se-á diante de uma conduta ativista ${ }^{15}$.

Possível frisar, neste contexto, que a decisão deve ser proferida sem a incidência de influências externas e escorada em um pensamento responsável, aplicando-se o direito de forma correta. Tal entendimento, aliás, encontra respaldo nas palavras de Lenio Streck:

Decidir é agir com responsabilidade política. Responsabilidade de meio (não resultado), de construir a reposta correta a partir do material jurídico básico (leis, códigos, precedentes, etc.) e dos princípios que conformam esse empreendimento coletivo (que remetem, por sua vez, a dimensões da dignidade humana). É uma questão de postura, pois, de atitude, diante de um problema jurídico (e não só moral e não só político e não só econômico). Responsabilidade de aplicar o direito corretamente. Uma questão de princípio: garantir os direitos de quem efetivamente os possui ${ }^{16}$.

Nesse viés, conclui-se que o julgador, quando da prolação da sua decisão, deve se pautar pelo autocontrole, sempre embasado pela criteriologia, limitando erros, incongruências e inconsistência, assim como anulando decisões incorretas, de sorte que a busca pela racionalidade deve sempre figurar como expoente.

\section{ATIVISMO JUDICIAL}

O ativismo judicial é um fenômeno originado nos estados Unidos. O registro mais antigo do termo é encontrado em um texto de 1947, divulgado na revista americana Fortune, cuja autoria pertence ao historiador e jornalista Arthur

\footnotetext{
15 STRECK, Lenio Luiz. Dicionário de Hermenêutica: quarenta temas fundamentais da teoria do direito à luz da crítica hermenêutica do direito. Belo Horizonte: Letramento, 2017, p. 259.

16 STRECK, Lenio Luiz. Dicionário de Hermenêutica: quarenta temas fundamentais da teoria do direito à luz da crítica hermenêutica do direito. Belo Horizonte: Letramento, 2017, p. 268.
} 
NISTLER, Regiane. Hermenêutica jurídica e intervencionismo judicial: conceitos gerais e fenômenos relacionados. Revista Eletrônica Direito e Política, Programa de Pós-Graduação Stricto Sensu em Ciência Jurídica da UNIVALI, Itajaí, v.14, n.2, $2^{\circ}$ quadrimestre de 2019. Disponível em: www.univali.br/direitoepolitica - ISSN 1980-7791

Schlesinger Jr. Referido autor do documento traçou o perfil de 9 (nove) juízes da Suprema Corte Americana e esta curiosidade é trazida à discussão por Teixeira:

[...] foi com o historiador Arthur Schlesinger Jr., em uma matéria da revista Fortune intitulada The Supreme Court: 1947, que o termo judicial activism entrou no léxico não apenas jurídico, mas sobretudo político e popular. Referindo à capacidade de desempenhar um papel afirmativo na promoção do bem-estar social, Schlesinger chamou de "ativistas judiciais" (judicial activists) os juízes Hugo Black, Willian O. Douglas, Frank Murphy e Wiley Rutledge. Já os juízes Felix Frankfurter, Harold Burton e Robert H. Jackson foram rotulados de "campeões do autocomedimento" (champions of self-restraint), por entenderem que o Judiciário não deve ir além do seu espaço limitado dentro do sistema estadunidense. Em uma posição intermediária, o presidente da Suprema Corte naquele ano, Frederick M. Vinson, e o juiz Stanley F. Reed não seriam plenamente caracterizáveis como desse ou daquele lado ${ }^{17}$.

É certo que a partir da publicação da matéria de Arthur a terminologia ganhou força em meio aos constitucionalistas da época. Reforça historicamente Ionilton Vale que "a expressão tem sido usada por alguns constitucionalistas dos Estados Unidos com uma perspectiva crítica, para imprecar um comportamento judicial não consoante à opinião jurisprudencial dominante"18. Todavia, inexistia consenso na época dos doutrinadores sobre a definição de ativismo judicial.

Para Vanice Valle, o ativismo judicial apresenta um dúplice sentido: ora é interpretado como um elemento finalístico - isto é, como um objeto capaz de estender direitos fundamentais - e ora entendido de elemento comportamental tendo em vista a prevalência dos juízos morais de cada julgador em particular, bem como a compreensão de cada qual do sentido das normas constitucionais ${ }^{19}$.

17 TEIXEIRA, Anderson Vichinkeski. Ativismo judicial: nos limites entre racionalidade jurídica e decisão política. Revista Direito GV, São Paulo. p. 037-058, Jun, 2012, p. 3.

18 VALE, Ionilton Pereira do. O ativismo judicial: conceitos e formas de interpretação. Disponível em: <https://ioniltonpereira.jusbrasil.com.br/artigos/169255171/o-ativismo-judicial-conceito-eformas-de-interpretacao>. Acesso em: 1 dez. 2018, p. 20.

19 VALLE, Vanice Regina do. Ativismo jurisdicional e o Supremo Tribunal Federal. Curitiba: Juruá, 2009, p. 20. 
NISTLER, Regiane. Hermenêutica jurídica e intervencionismo judicial: conceitos gerais e fenômenos relacionados. Revista Eletrônica Direito e Política, Programa de Pós-Graduação Stricto Sensu em Ciência Jurídica da UNIVALI, Itajaí, v.14, n.2, $2^{\circ}$ quadrimestre de 2019. Disponível em: www.univali.br/direitoepolitica - ISSN 1980-7791

Também discorre Ionilton Vale sobre as ambiguidades de sentido do termo ativismo judicial considerando que "O emprego da expressão 'ativismo judicial' sofreu, assim, um movimento pendular, ora foi associado a liberalismo, ora a conservadorismo. Cuidava-se, em um ou outro caso, de sinalizar um exercício distorcido da função jurisdicional"20. Contudo, majoritariamente, o sentido da expressão pende à concessão de excessiva liberdade ao magistrado.

Noutras palavras, o ex-ministro Barroso define o ativismo como "a atitude, a escolha de um modo específico e proativo de interpretar a constituição, expandindo o seu sentido de alcance"21. Ademais, Campos contextualiza a discussão datando o século XXI como o período histórico brasileiro no qual houve uma maior alteração quantitativa e qualitativa do espaço ocupado pelo STF, a exemplo da reinvenção da corte quanto à dimensão dos temas julgados, da argumentação decisória e da resolução além espaço institucional ${ }^{22}$.

Streck, Lepper e Tassinari, seguindo a linha da crítica hermenêutica, enxergam o ativismo judicial como uma tendência comportamental de juízes e tribunais a indexarem suas decisões judiciais a atos de vontade, valendo-se da supremacia do Judiciário para exercer atribuições não autorizadas pela CRFB/1988. Segue abaixo a síntese do pensamento comentado:

[...] o ativismo é gestado no seio do sistema jurídico. Tratase de conduta adotada pelos juízes e tribunais no exercício de suas atribuições. Isto é, a caracterização do ativismo judicial decorre da análise de determinada postura assumida por um órgão/pessoa na tomada de uma decisão que, por forma, é investida de juridicidade [...] E, no questionamento de como pode ser compreendida a manifestação judiciária, é possível encontrar posicionamentos que retrataram a indexação da decisão judicial a um ato de vontade daquele que julga. Desse modo, tem-se uma concepção de ativismo que pode ser

20 VALE, Ionilton Pereira do. O ativismo judicial: conceitos e formas de interpretação. Disponível em: <https://ioniltonpereira.jusbrasil.com.br/artigos/169255171/o-ativismo-judicial-conceito-eformas-de-interpretacao>. Acesso em: 1 dez. 2018, p. 20.

${ }^{21}$ BARROSO, Luís Roberto. Constituição, democracia e supremacia judicial: direito e política no Brasil contemporâneo. Revista de Direito do Estado. Salvador, v.21, 2011, p. 92.

22 CAMPOS, Carlos Alexandre de Azevedo. O ativismo judicial contemporâneo no Supremo Tribunal

Federal (STF) e nas cortes estrangeiras. 2015, p. 2. 
NISTLER, Regiane. Hermenêutica jurídica e intervencionismo judicial: conceitos gerais e fenômenos relacionados. Revista Eletrônica Direito e Política, Programa de Pós-Graduação Stricto Sensu em Ciência Jurídica da UNIVALI, Itajaí, v.14, n.2, $2^{\circ}$ quadrimestre de 2019. Disponível em: www.univali.br/direitoepolitica - ISSN 1980-7791

sintetizada como a configuração de um Poder Judiciário revestido de supremacia, com competências que não lhe são reconhecidas constitucionalmente ${ }^{23}$.

Fechando o ciclo conceitual, Campos defende que o "ativismo judicial é esse avanço das decisões do Supremo sobre os outros poderes"24. Evidencia, portanto, que o ativismo judicial está relacionado à invasão da tríplice esfera de poderes, nada mencionando acerca de uma marcante discricionariedade ou forte protagonismo judicial de juiz ou colegiado. No entanto, uma definição muito aberta pode ocasionar confusões terminológicas com a judicialização da polícia.

\section{JUDICIALIZAÇÃO DA POLÍTICA}

A compreensão plena do que vem a ser o fenômeno da judicialização da política exige a explicação anterior da existência de três importantes noções: o Direito, a Política e o Poder Judiciário. Todos possuem seus respectivos atributos e desígnios, entretanto, todos estão em constante intercâmbio, bem como da concepção do que seja constitucionalismo ${ }^{25}$.

Pensando neste entrosamento, não parece estranho imaginar que esta tríplice interação desencadeie, muitas vezes, intervenções ilegítimas de atribuições, eis uma das razões pela qual uma breve análise do movimento constitucionalista faz sentido neste momento. A respeito, Canotilho apresenta precisa definição:

Constitucionalismo é a teoria (ou ideologia) que ergue o princípio do governo limitado indispensável à garantia dos direitos em dimensão estruturante da organização políticosocial de uma comunidade. Neste sentido, o constitucionalismo moderno representará uma técnica específica de limitação do poder com fins garantísticos. O conceito de constitucionalismo transporta, assim, um claro

23 STRECK, Lenio Luiz; TASSINARI, Clarissa; LEPPER, Adriano Obach. O problema do ativismo judicial: uma análise do caso MS3326. Revista Brasileira de Políticas Públicas, Brasília, v. 5, Número Especial, 2015 p. 56-57.

24 CAMPOS, Carlos Alexandre de Azevedo. O ativismo judicial contemporâneo no Supremo Tribunal Federal (STF) e nas cortes estrangeiras. 2015, p. 2.

25 TASSINARI, Clarissa. Jurisdição e ativismo judicial: limites da atuação do judiciário. - Porto Alegre: Livraria do Advogado Editora, 2013, p. 28. 
NISTLER, Regiane. Hermenêutica jurídica e intervencionismo judicial: conceitos gerais e fenômenos relacionados. Revista Eletrônica Direito e Política, Programa de Pós-Graduação Stricto Sensu em Ciência Jurídica da UNIVALI, Itajaí, v.14, n.2, $2^{\circ}$ quadrimestre de 2019. Disponível em: www.univali.br/direitoepolitica - ISSN 1980-7791

juízo de valor. É, no fundo, uma teoria normativa da política, tal como a teoria da democracia ou a teoria do liberalismo ${ }^{26}$.

Extrai-se da citação acima que o constitucionalismo consiste em uma doutrina/ideologia normativo-política, que preconiza e busca defender a limitação dos poderes governamentais com o intuito de garantir direitos e manter a organização político-social de uma sociedade 27 .

Matteucci e Bobbio avigoram este preceito limítrofe da atuação governamental pela Constituição, justiçando-o na hierarquia de poder e na anterioridade de surgimento desta em relação àquele; condicionam ainda este caráter de constitucionalidade e legitimidade exclusivamente aos governos que observem seus ditames:

Convém ainda determo-nos um pouco em uma nova definição do Constitucionalismo, não muito frequente em nossa literatura política, que se baseia na oposição entre direito e poder, racionalidade e força. Parte de uma clara distinção entre Constituição e Governo. A Constituição, por ser anterior e superior ao Governo, pode limitar seu poder; quando violada, o Governo se torna anticonstitucional, arbitrário, ilegítimo ${ }^{28}$.

Perceptível é, neste contexto, o entrelaçamento dos aludidos elementos notadamente o Direito e a Política - e a relação de ambos com o constitucionalismo, que pode ser definido, segundo Tassinari "[...] como uma tentativa jurídica (Direito) de oferecer limites para o poder político (Política), o que se dá por meio das Constituições"29. Partindo deste raciocínio, Maciel e Koerner prosseguem com a origem e conceito de "judicialização da política":

A expressão passou a compor o repertório da ciência social e do direito a partir do projeto de C. N. Tate e T. Vallinder

\footnotetext{
26 CANOTILHO, J. J. Gomes. Direito Constitucional e Teoria da Constituição. Coimbra: Livraria Almedina, 1997, p. 45-46.

27 STAFFEN, Márcio Ricardo. Estado, constituição e juizados especiais federais. Rio de Janeiro: Lumen Juris, 2015.

28 BOBBIO, Norberto; MATTEUCCI, Nicola; et. al. Dicionário de política. Trad. Varriale, Carmen C. et. al; coord. trad. João Ferreira; ver. geral João Ferreira e Luis Guerreiro Pinto Cacais. - Brasília: Editora Universidade de Brasília. 11. ed. 1998, p. 256.

29 TASSINARI, Clarissa. Jurisdição e ativismo judicial: limites da atuação do judiciário. - Porto Alegre: Livraria do Advogado Editora, 2013, p. 28.
} 
NISTLER, Regiane. Hermenêutica jurídica e intervencionismo judicial: conceitos gerais e fenômenos relacionados. Revista Eletrônica Direito e Política, Programa de Pós-Graduação Stricto Sensu em Ciência Jurídica da UNIVALI, Itajaí, v.14, n.2, 20 quadrimestre de 2019. Disponível em: www.univali.br/direitoepolitica - ISSN 1980-7791

(1996), em que foram formuladas de linhas de análise comuns para a pesquisa empírica comparada do Poder Judiciário em diferentes países. "Judicialização da política" e "politização da justiça" seriam expressões correlatas, que indicariam os efeitos da expansão do Poder Judiciário no processo decisório das democracias contemporâneas ${ }^{30}$.

Continuam os autores, explicando a opção dos juristas pelo termo, haja vista que apropriadamente sinaliza a obrigação legal de sujeição temas tocantes às questões políticas (públicas) e familiares (privadas) ao Poder Judiciário:

Os juristas usam o termo judicialização para se referirem à obrigação legal de que um determinado tema seja apreciado judicialmente. Próximo a esse sentido, mas já com caráter normativo, afirma-se que judicialização é o ingresso em juízo de determinada causa, que indicaria certa preferência do autor por esse tipo de via. Refere-se a decisões particulares de tribunais, cujo conteúdo o analista consideraria político, ou referente a decisões privadas dos cidadãos (como questões de família). Decisões judiciais particulares poderiam ser sujeitas a escrutínio e seu conteúdo poderia ser avaliado como 'grau de judicialização'31.

Nunes Junior também se dignou trabalhar uma concepção à expressão judicialização da política. Em estrangeiro estudo traduzido, elucidou e reiterou algumas possíveis significações:

[...] a judicialização da política deve normalmente significar: 1) a expansão da jurisdição dos tribunais ou dos juízes a expensas dos políticos e/ou dos administradores, isto é, a transferência de direitos de tomada de decisão da legislatura, do gabinete ou da administração pública para os tribunais, ou, pelo menos; 2 ) a propagação dos métodos de decisão judiciais fora da jurisdição propriamente dita. Em resumo, podemos dizer que a judicialização envolve essencialmente transformar algo em processo judicial ${ }^{32}$.

\footnotetext{
30 MACIEL, Débora Alves; KOERNER, Andrei. Sentidos da judicialização da política: duas análises. Lua Nova [online]. 2002, n.57, pp.113-133. ISSN 0102-6445, p. 2.

31 MACIEL, Débora Alves; KOERNER, Andrei. Sentidos da judicialização da política: duas análises. Lua Nova [online]. 2002, n.57, p. 3.

32 NUNES JUNIOR. Tradução de Nunes Junior de fragmento da obra de TATE, Neal; VALLINDER, Torbjörn (org.). The global expansion of judicial power. New York, NY: New York Univ. Press, 1995, p. 13.
} 
NISTLER, Regiane. Hermenêutica jurídica e intervencionismo judicial: conceitos gerais e fenômenos relacionados. Revista Eletrônica Direito e Política, Programa de Pós-Graduação Stricto Sensu em Ciência Jurídica da UNIVALI, Itajaí, v.14, n.2, $2^{\circ}$ quadrimestre de 2019. Disponível em: www.univali.br/direitoepolitica - ISSN 1980-7791

Em complemento, Nunes faz uma minuciosa apreciação do excerto, sublinhando o aumento da jurisdição dos juízes e dos tribunais ao nível de adentrar na esfera decisória da legislatura e da administração pública e a propagação de técnicas decisórias procedimentais para setores que detinham anteriormente seus respectivos procedimentos, protocolos e diretrizes:

Por esse conceito, há dois aspectos a considerar em face da judicialização da política. O primeiro refere-se à transferência da tomada de decisão da arena administrativa (Poder Executivo) ou política (Poder Legislativo) para a arena judicial (Poder Judiciário). O segundo diz respeito à propagação do procedimento judicial para outros procedimentos: 0 administrativo e o legislativo ${ }^{33}$.

Doutrina Barroso que a judicialização da política é o responsável por redirecionar o foco decisório de questões político-sociais, geralmente incumbências do Poder Legislativo e do Poder Executivo, para o Poder Judiciário, realizando alterações linguísticas, argumentativas e na democracia:

Judicialização significa que algumas questões de larga repercussão política ou social estão sendo decididas por órgãos do Poder Judiciário, e não pelas instâncias políticas tradicionais: o Congresso Nacional e o Poder Executivo - em cujo âmbito se encontram o Presidente da República, seus ministérios e a administração pública em geral. Como intuitivo, a judicialização envolve uma transferência de poder para juízes e tribunais, com alterações significativas na linguagem, na argumentação e no modo de participação da sociedade ${ }^{34}$.

Ultrapassada esta fase de conceituação da judicialização da política e do ativismo judicial, serão explorados nos tópicos seguintes algumas distinções existentes entre estes dois fenômenos, além de apresentados alguns riscos inerentes deste intervencionismo judicial no panorama brasileiro.

33 NUNES JUNIOR, Amandino Teixeira. A judicialização da política no Brasil: estudo de caso de comissões parlamentares de inquérito e fidelidade partidária. - Brasília: Câmara dos Deputados, Edições Câmara, 2016, p. 21.

34 BARROSO, Luís Roberto. Judicialização, ativismo judicial e legitimidade democrática. Revista Consultor Jurídico. 2008, p. 2. 
NISTLER, Regiane. Hermenêutica jurídica e intervencionismo judicial: conceitos gerais e fenômenos relacionados. Revista Eletrônica Direito e Política, Programa de Pós-Graduação Stricto Sensu em Ciência Jurídica da UNIVALI, Itajaí, v.14, n.2, 20 quadrimestre de 2019. Disponível em: www.univali.br/direitoepolitica - ISSN 1980-7791

\section{DIFERENCIANDO ATIVISMO JUDICIAL E JUDICIALIZAÇÃO DA POLÍTICA}

Não é incomum encontrar quem confunda ativismo judicial e judicialização da política, tratando ambos os fenômenos como se fossem sinônimos. A maior razão para esta confusão é que as duas expressões são utilizar para representar uma atuação do Judiciário que extrapola sua competência constitucional.

Todavia existe uma distinção terminológica, ideológica e prática que as desassemelham. Nesta linha de raciocínio, Medeiros aponta uma característica de volição pessoal do julgador quando da escolha da interpretação normativa pelo julgador nas hipóteses de ativismo judicial; assinala, contudo, a escolha de um modelo constitucional no caso da judicialização. Nas palavras do autor:

Há, porém, diferenças as quais definem o que realmente significam essas expressões na prática: o ativismo implica opções, escolhas por parte dos juízes quando da interpretação das regras constitucionais, ao passo que a judicialização decorre da adoção de determinado paradigma constitucional em vez de ação de vontade política individual ${ }^{35}$

Corroboram outros juristas, dentre eles Streck, com este posicionamento ao descomplicarem os significados destes dois fenômenos evidenciando a ocorrência da carga decisória moralista ou política exercida pelos juízes no caso do ativismo judicial e da invasão de poderes pelo Poder Judiciário:

[...] um juiz pratica ativismo quando decide a partir de argumentos de política, de moral, enfim, quando o direito é substituído pelas convicções pessoais de cada magistrado (ou de um conjunto de magistrados); já a judicialização da política é um fenômeno que exsurge a partir da relação entre os poderes do Estado (pensemos, aqui, no deslocamento do polo de tensão dos poderes Executivo e Legislativo em direção da justiça constitucional) ${ }^{36}$.

35 MEDEIROS, Aragão João Carlos de. Judicialização da política no Brasil: influência sobre atos interna corporis do Congresso Nacional. - Brasília: Câmera dos Deputados, Edições Câmara, 2013, p. 70-71.

36 STRECK, Lenio Luiz. Direito. In: BARRETTO, Vicente de Paulo; CULLETON, Alfredo (Coords.).

Dicionário de filosofia política. São Leopoldo: Editora Unisinos, 2010, p. 145-150. 
NISTLER, Regiane. Hermenêutica jurídica e intervencionismo judicial: conceitos gerais e fenômenos relacionados. Revista Eletrônica Direito e Política, Programa de Pós-Graduação Stricto Sensu em Ciência Jurídica da UNIVALI, Itajaí, v.14, n.2, $2^{\circ}$ quadrimestre de 2019. Disponível em: www.univali.br/direitoepolitica - ISSN 1980-7791

Complementarmente, Tassinari comenta sobre a relação entre Política e Direito, sobre a implicação do ativismo judicial e de sua desambiguação com a judicialização da política:

[...] Primeiro, não há como negar o elo existente entre Direito e Política; Segundo, a inter-relação entre Direito e Política não autoriza a existência de ativismos judiciais; Terceira, há um equívoco em considerar judicialização da política e ativismo judicial como se fossem o mesmo fenômeno; E quarto, a judicialização da política é um fenômeno contingencial, isto é, no sentido de que insurge na insuficiência dos demais poderes, em determinado contexto social, independente da postura de juízes e tribunais, ao passo que o ativismo diz respeito a uma postura do Judiciário para além dos limites constitucionais ${ }^{37}$.

Constata-se do retro transcrito, que a autora acredita que o ativismo judicial conforma uma atuação extra limites constitucionais ao passo que a judicialização (da política) considera o caso a caso sob judice nos quais os poderes Legislativo e Executivo não são capazes de cumprir suas atribuições.

Vale-se novamente da analogia do ex-ministro Barroso, especialmente quanto ao seu comentário distinguindo os dois fenômenos judiciais in quaestio:

A judicialização e o ativismo judicial são primos. Vêm, portanto, da mesma família, frequentam os mesmos lugares, mas não têm as mesmas origens. Não são gerados, a rigor, pelas mesmas causas imediatas. A judicialização, no contexto brasileiro, é um fato, uma circunstância que decorre do modelo constitucional que se adotou, e não um exercício deliberado de vontade política. Em todos os casos referidos acima, o Judiciário decidiu porque era o que Ihe cabia fazer, sem alternativa ${ }^{38}$.

Traduzindo a analogia e comentário de Barroso, percebe-se a existência de um elemento volitivo no ativismo judicial e a existência de uma modelagem constitucional na judicialização da política, justificando-se esta última na proteção

\footnotetext{
37 TASSINARI, Clarissa. Jurisdição e ativismo judicial: limites da atuação do judiciário. - Porto Alegre: Livraria do Advogado Editora, 2013, p. 36-37.

38 BARROSO, Luís Roberto. Judicialização, ativismo judicial e legitimidade democrática. Revista Consultor Jurídico. 2008, p. 6.
} 
NISTLER, Regiane. Hermenêutica jurídica e intervencionismo judicial: conceitos gerais e fenômenos relacionados. Revista Eletrônica Direito e Política, Programa de Pós-Graduação Stricto Sensu em Ciência Jurídica da UNIVALI, Itajaí, v.14, n.2, $2^{\circ}$ quadrimestre de 2019. Disponível em: www.univali.br/direitoepolitica - ISSN 1980-7791

pelo Judiciário das imposições constitucionais ao executar atribuições que estariam fora de sua alçada.

\section{CONSIDERAÇÕES FINAIS}

Os materiais pesquisados e analisados e os registros constantes no presente artigo revelam uma diferente perspectiva sobre a complexidade e aplicabilidade da hermenêutica jurídica no cenário brasileiro. Referida área de estudo, uma com a qual os acadêmicos e profissionais do direito não parecem muito familiarizados, apresenta riquíssimos aportes doutrinários e tecnicistas ao campo interpretativo normativo, descortinando seus fenômenos conexos.

Uma desta notáveis contribuições da hermenêutica jurídica reside no exame da discricionariedade judicial, espécie de abstracionismo moral ou exercício arbitrário individual, utilizada por julgadores ou colegiados como prerrogativa para atuarem fora de suas jurisdições. Valendo-se desta margem volitiva maior, acabam incidindo em condutas marcadas por ativismo e/ou politização, comportamentos estes crescentes na realidade jurídica nacional.

Neste sentido, hermeneuticamente pensando, busca-se ferramentais racionais capazes de debelar - ou ao menos minimizar - aludida discricionariedade judicial que também não se confunde com a da administração pública - como a teoria da decisão e a resposta correta, técnicas que, grosso modo, pautam-se na criteriologia, no desprovimento de pré-conceitos, preconceitos e condicionantes morais em favor da melhor decisão.

Com este espírito interpretativo mais tecnicista trazido pela hermenêutica jurídica, debruça-se sobre os fenômenos do ativismo judicial e da judicialização da política com objetivo de os compreender e de antever suas consequências. A necessidade desta precaução jaz no fato de que muitos julgadores assumem posturas ativistas (por moralismos, interesses, etc.) ou politizadas (por irregularidade, ineficiência, etc. das instituições) extrapolando suas alçadas. 
NISTLER, Regiane. Hermenêutica jurídica e intervencionismo judicial: conceitos gerais e fenômenos relacionados. Revista Eletrônica Direito e Política, Programa de Pós-Graduação Stricto Sensu em Ciência Jurídica da UNIVALI, Itajaí, v.14, n.2, $2^{\circ}$ quadrimestre de 2019. Disponível em: www.univali.br/direitoepolitica - ISSN 1980-7791

Pelo retrospecto constitucional histórico brevemente construído no artigo foi possível contextualizar estes dois referidos fenômenos. O constitucionalismo, consistente em doutrina/ideologia normativo-política, preza pela limitação dos poderes governamentais, pela concretização dos direitos fundamentais e manutenção da sociedade, características compatíveis com a tríplice noção de direito-políticaconstituição que está interligada com tais fenômenos jurídicos.

Igualmente é possível concluir que, embora facilmente confundíveis, o ativismo judicial e a judicialização da política se distinguem um do outro pelas suas causas de origem. Enquanto o ativismo judicial advém de um voluntarismo pessoal, de uma carga decisória moralista do magistrado, a judicialização provém de uma escolha de modelo constitucional. Fato é que ambos possuem uma margem volitiva e que cruzam fronteiras atributivas em favor do Judiciário.

\section{REFERÊNCIA DAS FONTES CITADAS}

BARROSO, Luís Roberto. Constituição, democracia e supremacia judicial: direito e política no Brasil contemporâneo. Revista de Direito do Estado. Salvador, v.21, 2011.

Judicialização, ativismo judicial e legitimidade democrática. Revista Consultor Jurídico. 2008.

BOBBIO, Norberto; MATTEUCCI, Nicola; et. al. Dicionário de política. Trad. Varriale, Carmen C. et. al; coord. trad. João Ferreira; ver. geral João Ferreira e Luis Guerreiro Pinto Cacais. - Brasília: Editora Universidade de Brasília. 11. ed. 1998.

CAMPOS, Carlos Alexandre de Azevedo. $\mathbf{O}$ ativismo judicial contemporâneo no Supremo Tribunal Federal (STF) e nas cortes estrangeiras. Disponível em: <https://www.academia.edu/12379284/O_ativismo_judicial_contempor\%C3\%A 2neo_n o_STF_e_nas_Cortes_estrangeiras>. Acesso em: 1 dez. 2018.

CANOTILHO, J. J. Gomes. Direito Constitucional e Teoria da Constituição. Coimbra: Livraria Almedina, 1997.

DELFINO, Lúcio; LOPES, Ziel Ferreira. STRECK, FONSECA COSTA, KAHNEMAN E TVERSKY: todos contra o ativismo judicial probatório de Michele Taruffo. Revista de Processo (RePro). 255, 2016. 
NISTLER, Regiane. Hermenêutica jurídica e intervencionismo judicial: conceitos gerais e fenômenos relacionados. Revista Eletrônica Direito e Política, Programa de Pós-Graduação Stricto Sensu em Ciência Jurídica da UNIVALI, Itajaí, v.14, n.2, $2^{\circ}$ quadrimestre de 2019. Disponível em: www.univali.br/direitoepolitica - ISSN 1980-7791

FREITAS, Juarez. A Hermenêutica Jurídica e a Ciência do Cérebro: Como Lidar com os Automatismos Mentais. Revista Ajuris. 130. Porto Alegre: Associação dos Juízes do Rio Grande do Sul, 2013.

MACIEL, Débora Alves; KOERNER, Andrei. Sentidos da judicialização da política: duas análises. Lua Nova [online]. 2002, n. 57, p.113-133. ISSN 01026445.

MEDEIROS de, Aragão João Carlos. Judicialização da política no Brasil: influência sobre atos interna corporis do Congresso Nacional. - Brasília: Câmara dos Deputados, Edições Câmara, 2013.

NUNES JUNIOR, Amandino Teixeira. A judicialização da política no Brasil: estudo de caso de comissões parlamentares de inquérito e fidelidade partidária. - Brasília: Câmara dos Deputados, Edições Câmara, 2016.

STAFFEN, Márcio Ricardo. Magistrati. Novos Estudos Jurídicos, Itajaí, v. 18, n. 3, p. 569-570, dez. 2013.

STAFFEN, Márcio Ricardo. Estado, constituição e juizados especiais federais. Rio de Janeiro: Lumen Juris, 2015.

STRECK, Lenio Luiz. Dicionário de hermenêutica: quarenta temas fundamentais da teoria do direito à luz da crítica hermenêutica do Direito. Belo Horizonte (MG): Letramento, 2017.

Direito. In: BARRETTO, Vicente de Paulo; CULLETON, Alfredo (Coords.).

Dicionário de filosofia política. São Leopoldo: Editora Unisinos, 2010.

; TASSINARI, Clarissa; LEPPER, Adriano Obach. O problema do ativismo judicial: uma análise do caso MS3326. Revista Brasileira de Políticas Públicas, Brasília, v. 5, Número Especial, 2015 p. 51-61.

TASSINARI, Clarissa. Jurisdição e ativismo judicial: limites da atuação do judiciário. - Porto Alegre: Livraria do Advogado Editora, 2013.

TERRA, Aline de Miranda Valverde. A discricionariedade judicial na metodologia civil-constitucional. Revista da Faculdade de Direito - UFPR. Curitiba, vol 60, n. 3. Set/dez. 2015. p. 368. Disponível em: <DOI: 10.5380/rfdufpr.v60i3.41141>. Acesso em: 01 dez. 2018.

TEIXEIRA, Anderson Vichinkeski. Ativismo judicial: nos limites entre racionalidade jurídica e decisão política. Revista Direito GV, São Paulo. p. 037058, Jun, 2012.

VALE, Ionilton Pereira do. $\mathbf{O}$ ativismo judicial: conceitos e formas de interpretação. Disponível em: <https://ioniltonpereira.jusbrasil.com.br/artigos/169255171/o-ativismo-judicialconceito-e-formas-de-interpretacao>. Acesso em: 1 dez. 2018.

VALLE, V. R. Lirio do. Ativismo jurisdicional e o Supremo Tribunal Federal. 
NISTLER, Regiane. Hermenêutica jurídica e intervencionismo judicial: conceitos gerais e fenômenos relacionados. Revista Eletrônica Direito e Política, Programa de Pós-Graduação Stricto Sensu em Ciência Jurídica da UNIVALI, Itajaí, v.14, n.2, 20 quadrimestre de 2019. Disponível em: www.univali.br/direitoepolitica - ISSN 1980-7791

Curitiba: Juruá, 2009.

RECEBIDO EM: 16/05/2019

APROVADO EM: 22/07/2019 